\title{
Sender Dovchin*
}

\section{Uneven distribution of resources in the youth linguascapes of Mongolia}

DOI 10.1515/multi-2015-0065

\begin{abstract}
Drawing on offline and online casual interactions in the context of youth in Mongolia, on the Asian periphery, this article looks at youth mixed language practices from the perspective of "linguascapes" in order to capture the current flows of transnational linguistic resources in relation to other social landscapes. The study seeks to contribute to current discussions of the sociolinguistics of globalization by investigating to what extent and in what way resources make up linguascapes among youth groups with different access to resources. The main implication of this study is that youth linguascapes in Mongolia are fundamentally diverse, as a result of the combination of varied transcultural resources. At the same time, these resources are unevenly distributed and unequally localized.
\end{abstract}

Keywords: youth linguascapes, transnational flows, uneven distribution of resources, sociolinguistics of globalization, Mongolia

\section{Introduction}

It is by now a truism that young people who are not necessarily subject to transnational migration are nevertheless engaged with linguistic and cultural diversity via media, technology and other available resources (Sharma 2012; Sultana et al. 2013, 2015). For example, young adults in the peripheries have access to a varied amalgam of linguistic and semiotic resources, producing a range of social and cultural identities (Pietikainen and Kelly-Holmes 2013). They create locally relevant new meanings and new languages by relocalizing available resources embedded within popular culture, new media and virtual space (Higgins 2009, 2013). Sharma (2012) elaborates the example of economically and educationally privileged undergraduate college students in Nepal with direct access to social media, mediascape and global Englishes who innovatively mix English and Nepali in order to construct their bilingual identities and recontextualize both local and global media content. Likewise, elite university students

*Corresponding author: Sender Dovchin, University of Technology Sydney, 15 Broadway, Ultimo New South Wales 2007, Australia, E-mail: Sender.Dovchin@alumni.uts.edu.au 
in Bangladesh with direct access to English and Western media use stylised English and Bangla, negotiating attributes of identity in the process. With their creative and strategic integration of English, these young adults go beyond its linguistic and cultural boundaries, making Bangla linguistically unique (Sultana 2014: 40).

However, the resources that make up linguistic bricolage in different ways among different youth groups and the way they link up with wider social stratification and inequality of access remain a mystery. This article thus seeks to complement the horizons of these previous studies by examining to what extent linguistic and semiotic resources are in fact distributed and disseminated around peripheral young speakers with uneven access to resources. The research is timely considering current discussions of the sociolinguistics of globalization, with the majority of the aforementioned studies focusing mainly on youth groups with direct and easy access to varied resources, leaving out the important issues pertaining to other youth groups with less access to resources.

Drawing on the conceptual frameworks of "linguascape" and the research methodology of "linguistic (n)ethnography", this article discusses the cases of uneven localizing processes of linguistic and cultural resources integrated within contemporary youth linguistic bricolage focusing on specific examples from Mongolia - a nation in the Asian periphery. Two main questions will be investigated: (1) How and why do young adults in Mongolia integrate varied transnational resources within their daily linguistic diversity? (2) To what extent are these transnational resources distributed in the linguistic diversity of youth in Mongolia? The first question will not only deal with the internal organizations and linguistic patterns of youth linguistic bricolage in Mongolia, but also with its external sociocultural meanings and factors. The second question will specifically address the uneven distributive conflicts of linguistic and cultural resources amongst youth linguistic diversity in Mongolia. Overall, this article seeks to shed light on a critical sociolinguistic discussion of unequal distributive conflicts of resources amongst young speakers, a new standpoint that is as yet under-researched in the existing literature of the sociolinguistics of globalization (Dovchin et al. 2016).

\section{The emergence of youth linguistic bricolage in Mongolia}

Mongolia has opened itself up to the outside world since 1990, with its transformation from a communist society (a satellite of the former Soviet 
Union) to a democratic society. Prior to 1990, Mongolia was a socialist country isolated from the rest of the world. Russian was the dominant foreign language in the sociolinguistic arena of Mongolia, whilst other linguistic and cultural elements from the West were essentially avoided. In 1941, the socialist Mongolian government replaced the classic Mongolian Uyghur script with the Cyrillic alphabet, which has remained the standard orthographic system of Mongolia and is known as Cyrillic Mongolian (Dovchin 2011; Dovchin 2015).

Following the collapse of the Soviet Union and communist rule in 1990, Mongolia and its capital city, Ulaanbaatar (UB), has witnessed a major shift in lifestyle, with young urban Mongolians actively engaged with globalization. Young Mongolians have become particularly open to the idea of "linguistic diversity": they have already adopted a "laissez-faire policy" when it comes to the spread of foreign languages in Mongolia, welcoming diversity rather than asserting the use of one language or another. The language policy of "English plus one other language" is prevalent amongst the youth population. The more languages you speak, the better opportunities you will have, according to a popular Mongolian proverb ("Heltei bol hultei" ['If you have language, you have legs']). Increase in linguistic diversity in Mongolia has been phenomenal, with English and other languages such as Korean, Japanese, Chinese, French, German, Spanish and Turkish starting to feature in various contexts, institutional and non-institutional alike, replacing the once popular Russian. As Dovchin (2015: 440) notes, "Young urban Mongolians follow the styles of Western celebrities; young boys dream of wrestling in Japanese professional sumo (the major grand champions of Japanese sumo are Mongolians); they watch Korean and Chinese TV dramas; they attend varied multilingual singing talent shows". It is quite common for young Mongolians to practice linguistically mixed activities within their daily casual online and offline in-peer interactions (Dovchin 2015).

Following the development of this post-revolutionary diversity, a handful of scholars started to explore youth linguistic bricolage in Mongolia. Billé (2010) notes the significance of English and the Latin script in the contemporary musical landscape in Mongolia, with the vast majority of young singers and bands titling themselves in English or Latin, and online consumers of varied Mongolian websites using predominantly the transliterated Roman Mongolian orthographic system, instead of official Cyrillic Mongolian. Likewise, Beery (2004) observed on multiple occasions how young Mongolians send SMS texts to each other using English and other Latin script languages. As Dovchin (2011: 331) proposes, youth linguistic diversity in Mongolia should be understood in relation to creative practice that provides urban youth with alternative ways of 
being modern young Mongolians. It is a case of "transient, hybrid and fluid soundscapes and linguascapes”, which are being reproduced by young urban Mongolians in negotiation with both global and local linguistic flows. Sultana et al. (2015) conclude that young Mongolians transgress between various linguistic resources and their chosen cultural forms. Engaging in processes of stylization, they also produce novel linguistic possibilities, as well as particular constructions of themselves and their interlocutors.

It is clear from these previous studies that young Mongolians are indeed creatively engaged with current transnational linguistic resources, yet it is still not clear to what extent these resources are in fact distributed and disseminated amongst speakers with uneven access. This is an important and timely issue considering the increasing inequality generated by the new market economy in post-socialist Mongolia. Following the liberalization of the economy in 1990, many Mongolians started to benefit from the new opportunities that arose, particularly business entrepreneurs and the educated. However, there are still large numbers of Mongolians who are clearly struggling to survive on a day-today basis. As renowned historian Nasan Dashdendeviin Bumaa notes, "Mongolia has achieved its goals, that is, independence and democracy within a market economy structure, but the cost has been high. Many lost their lives; even more suffered from economic, physical and human rights deprivations during the frequent periods of restructuring; and the incessant intergenerational struggle continues" (cited in Cohen 2004: 4). The gap between rich and poor has started to widen, resulting in obvious uneven social class positions in society, as the "richest 20 percent of the population consumes five times the amount consumed by the poorest 20 percent of the population" (Mongolian Economy Journal [MEJ] 2013: paras. 2-3). This increasing inequality divides current households in UB as “"wealthy”, "better-off”, “average”, “middle-income”, "poor” and "very poor"' (MEJ 2013: paras. 2-3). More than half of the total UB population lives in the "ger districts", which are situated on the outskirts of Ulaanbaatar, and lack basic access to water, sanitation and infrastructure. Most of the families live in the "ger" [traditional Mongolian felt dwelling] or small houses. Residents live without central heating, using their own manual coal stoves, and outdoor wooden toilets pitched on dug pits. These ger district residents are generally perceived as "poor" or sometimes "very poor". Meanwhile, people living in city apartments, educated at universities and working for public and private institutions, are generally classified as "average" and "middle-income". Very few politicians and top business entrepreneurs are perceived as "wealthy", despite the fact that they own large family houses in the affluent district of UB, drive luxury cars, and send their children overseas for educational and travel opportunities. 


\section{The conceptual framework: "uneven resources" and "linguascapes"}

A recent trend in the sociolinguistics of globalization has been concentrated on capturing the increasing complexity of linguistic and semiotic resources circulating among transnational citizens around the world. This study thus draws first of all on an understanding of "linguascape" (Dovchin 2016a; Dovchin 2016b; Pennycook 2003; Rantanen 2006; Steyaert et al. 2011), a term originally developed by extending the notion of "-scapes" (Appadurai 1996, 2001, 2006) to refer to "the transnational flows of linguistic resources circulating across the current world of flows, making meanings in contact with other social scapes and affecting the particular speakers' linguistic practices in varied ways" (Dovchin 2016a: 4; Dovchin 2016b). This earlier understanding of linguascape focused on the ways in which the current global cultural economy is understood in terms of non-isomorphic transnational movements of the social landscapes of people, imageries, technologies, money, and ideas (i. e. ethno-, media-, techno-, financeand ideoscapes) to demonstrate the various ways that cultural objects move across boundaries to make meaning (Thorne and Ivković 2015). As Martin-Jones and Gardner (2012) emphasize, these scapes are diversifying and integrating with one another at high speed and volume, resulting in varied new multilingual scapes. Sharma (2012: 502-505) notes that exploring the flows of languages in relation to the "scapes" allows us to see the opportunity to recognize the language flows not necessarily as one-directional, travelling from the center to the periphery, but also from the periphery to the global. Steyaert et al. (2011: 270) observe that linguascape captures "the complexity of multilingual communication" and the flow of languages that cross a specific discursively mediated space. Jaworski etal. (2003: 19) view linguascape as a creative force and a product of moving languages, be it domestic or host, and their accompanying meanings. As Dovchin (2016a: 4) reiterates, linguascape is "a large repository of mobile linguistic resources in miscellaneous forms - the combination of multiple linguistic resources, diffused by multiple resources such as codes, registers, features, styles, genres, voices and symbols - hastened by other social scapes, opening up new linguistic opportunities and meanings for local contexts".

The analytic potential of linguascape can be expanded through a stronger focus on the need to understand how varied linguistic, semiotic and cultural resources are disseminated, circulated and mobilized by and across dissimilar speakers with different access to resources to produce varied linguascapes. Appadurai $(1996,2006)$ iterates that these scapes are profoundly unpredictable and unevenly localizing yet overlapping and lapping disjunctures, intensely 
producing local forms of problems. The disjuncture between these landscapes thus may produce some form of intersection or unevenness of conflicting local meanings. The speed and volume of each of these scapes are now so great that the disparity and inequality have become central to the politics of the global cultural economy. From this perspective, linguascape is understood as being created by uneven linguistic resources circulating across different speakers with unequal socioeconomic backgrounds. As Heller (2010: 349) suggests, we are living in an age of capital expansion, which generates the movement of basic primary resources and products into diverse zones. Consequently, new conditions for the production of language practices seem to emerge, which need to be reimagined as "communicative resources, socially constructed in uneven, unequal, distributed social spaces”. Resources are unevenly distributed through communicative networks in ways which make them more or less accessible to speakers. Heller (2007: 2) thus refers to current global linguistic resources, following Bourdieu, as "a set of resources which circulate in unequal ways in social networks and discursive spaces, and whose meaning and value are socially constructed within the constraints of social organizational processes, under specific historical conditions". In other words, linguistic resources are not equally disseminated in any given community, despite the fact that all individuals of the community may share the same values (Heller 1992: 125). This uneven distribution of resources ultimately becomes the driving force of the linguistic operation, reproducing relations of language power and language capital.

Central to Blommaert and Dong's (2010: 368) assessment of the sociolinguistics of mobility in current globalization, in which "language-in-motion" is constituted by various spatiotemporal frames interacting with one another (i. e. "scales") is the idea that language patterns are organized around different levels of layers. Here, "[a]ccess to, and control over, scales is unevenly distributed", since it is a case of power and inequality (Blommaert and Dong 2010: 368). Clear examples of this uneven distribution can be demonstrated within resources for access to the higher scales - "a sophisticated standard language variety, or advanced multimodal and multilingual literacy skills” (Blommaert and Dong 2010: 368). It should be noted, however, that the question of what counts as high and low scales or greater and lower mobilities may have multiple facets since, for example, standard language may also not be equivalent to higher scale. Linguistic practices that are "low scale" may also become powerful or prestigious because of their recontextualization or because of the importance of local over global identities, affiliations, and articulations (Blommaert 2010; Blommaert and Backus 2013). Mesthrie (2015) points out the ways that non-conventional varieties of mixed languages may, by and large, be associated with greater privilege, since speakers who 
engage in linguistic mixing are likely to be those in higher socioeconomic classes than people whose linguistic practices come closer to what is assumed to be standard (see also Dovchin etal. 2016). As Blommaert and Dong (2010: 368) further note, “The spaces are always someone's space, and they are filled with norms, expectations, conceptions of what counts as proper and normal (indexical) language use and what does not." The speakers never move across empty spaces, because mobility is a trajectory through different spaces - "stratified, controlled, and monitored ones", where language "gives you away" (Blommaert and Dong 2010: 368). Large and small disparities in language use may locate the speaker in specific level of social indexicality. There are "multiple layers of normativity in the form of self-, peer- and state-imposed norms" (Varis and Wang 2011: 71), in which diversity is coordinated and regimented.

In sum, one of the key characteristics of current transnational linguistic flows is the idea that the inconsistency and disparity of resources are contributing to the uneven distribution and access to linguistic and communicative resources. Not all speakers have control over or access to certain resources, since the uneven localizing processes of certain linguistic resources are often caused by an uneven distribution of other resources, whose meanings are socially, ideologically and historically constructed, depending on the specific local circumstances (Dovchin et al. 2016).

\section{Research methodology: Linguistic (n)ethnography}

The data used in this article derive from a larger "linguistic (n)ethnographic research methodology": the combination of two methods - linguistic ethnography and netnography - considering the fact that linguascapes may occur both in offline casual conversations and online electronic communications. The project looked into the linguascapes of young adults living in Ulaanbaatar, Mongolia (conducted between July and November 2010; and between April and June 2011). Overall, 40 students from various social backgrounds aged between 17 and 29 years from the National University of Mongolia (NUM) volunteered to participate in the research. Their socioeconomic and regional backgrounds were diverse, varying from affluent to poor and from rural to urban, before they gained admission to university and came to live in Ulaanbaatar. Following linguistic ethnographic methods (Rampton et al. 2004; Tusting and Maybin 2007), casual face-to-face conversations among students were recorded during classroom breaks, libraries, lecture halls and university coffee shops. Participants were provided with digital recorders and recorded their own conversations on their own terms whenever they spent time with their peers. 
Meanwhile, virtual ethnographic analytic frameworks such as "netnography" (Kozinets 2002, Kozinets 2015) and "Internet/online ethnography" (Androutsopoulos 2006; Stæhr 2015) were employed to look at the virtual linguistic behaviours of Facebook (FB) users throughout the entire timeline of the research project (from July 2010 until December 2015). FB was chosen as the main research site due to its widespread popularity in recent years. FB plays a significant role in the daily linguistic repertoires of people around the world (de Bres 2015), involving semiotic, heteroglossic and linguistic creativity. As Leppänen et al. (2015: 4) point out, superdiversity in social media is realized by "the mobility and mobilization of linguistic and other semiotic resources that are distributed, recontextualized and resemiotized in various ways in countless and rhizomatic digital media practices mushrooming on the internet" (see also Leppänen et al. 2009).

FB discourse is understood as the everyday language activities of young adults in Mongolia, following Stæhr (2015: 44): “[youth] spoken and written discursive practices seem to be part of similar processes of enregisterment, because everyday language use on Facebook indicates that the normative orientations and value ascriptions to particular language forms correspond to those found in speech". It is therefore important for sociolinguists to include everyday digital media practices when inquiring into the language practices of contemporary youth. In so doing, I sent FB requests to the research participants and added them to my own personal FB account as soon as they agreed to take part in the research project. Data collection started from the moment the friendship was established. The reason I used my own personal FB account was the issue of credibility and sincerity. Inviting the research participants to become my FB friend made them feel safe rather than that they were simply being used as research subjects. Moreover, it created an instant relationship of sincerity between the researcher and the participants. This is not to say, however, that I necessarily engaged in frequent FB interaction with my participants. Rather, I sought to observe the participants' language practices on FB, employing a natural and unobtrusive manner. In so doing, I tried to actively avoid interacting with my FB research participants. I also had to restrict my research participants from viewing some of my own personal FB activities; they were only approached by me through private FB messaging, as the need arose.

The data gained from "linguistic (n)etnography" was later analyzed using a "transtextual analytic framework" (Dovchin et al. 2015; Pennycook 2007; Sultana et al. 2015) in order to reveal the complexity embedded within linguascapes. This framework suggests that "[...] texts have meaning not in themselves but only when used; they need to be understood productively, contextually and discursively" because "they have histories, they are contextually influenced, and they occur within larger frameworks of meaning” (Pennycook 2007: 53). 
According to this point of view, the data was analyzed through a set of interpretive and discursive tools involving pretextual history (sociohistorical implications of the text); contextual relations (the physical location and the indexical meaning in the actual text); subtextual meaning (the sociocultural ideologies and the relations of power that affect the text); intertextual echoes (the covert associations with other texts); and post-textual interpretation (the metalinguistic interpretations of the speakers' own texts via face-to-face and Facebook chat systems) (Pennycook 2007; see also Dovchin 2015).

\section{Data presentation: The distribution of uneven resources}

I have selected eight data extracts for this data presentation section from the hundreds of pages of data that the (n)ethnography has yielded, with the primary aim of introducing a range of linguistic and cultural resources that young speakers make use of in their linguascapes. The eight data extracts were also selected because of the explicit posttextual interpretations generously provided by my four research participants, who willingly shared with me their own sociolinguistic practices. The extracts are also categorized into two separate sub-sections to elaborate the linguascapes of young adults with diverse socioeconomic backgrounds, from affluent to underprivileged. However, since the research has been restricted to a limited number of NUM students, these examples cannot fully represent the linguascapes of all NUM students, and certainly not those of the wider population of young adults in Mongolia. The first two extracts demonstrate the linguascapes of privileged young adults with direct and higher access to scapes, while the last two extracts show the less affluent linguascapes of youth with less and lower access to resources. All names of both individuals and institutions at NUM in this study are pseudonyms to protect anonymity. All Mongolian texts used in the data examples are translated from Mongolian into English by the researcher. All Cyrillic Mongolian texts were transliterated into Roman script in order to make the Mongolian text accessible to non-Mongolian speakers.

\subsection{Uneven resources in the linguascapes of privileged youth}

In this sub-section, I offer analyses of the linguascapes of young adults from a privileged background in Mongolia. The linguascapes of these affluent young speakers are created by higher mobility and greater access to transnational resources. They are actively involved in the creative processes of relocalizing 
varied linguistic and cultural resources in the context of both their face-to-face and online casual interactions.

Extract 1 is associated with a casual conversation between three speakers (senior students, majoring in business administration at NUM) during their classroom break time (Oldokhbayar [21, male, UB born] and Naran [22, female, rural born], a young couple who have been in a romantic relationship since the first year of their university studies, and their classmate, Dorj [20, male, UB born]). The focus will be on the linguascapes of Naran and her boyfriend, who integrate a substantial amount of linguistic and cultural resources in their conversations.

Extract 1 (see Appendix for transcription conventions)

Language guide: Mongolian - regular font; English - italics; Japanese underlined

1 Oldokhbayar: ...Oroi yamar plantai khairaa? Unuu oroi bolovsrol channel deer

2

3

Kurisowagiin "Seven Samurai” garna gesenshuu. Highly

recommended!

'Do you have a plan for tonight, love? Kurisowa's "Seven Samurai”

is on tonight at Education channel. Shall we watch in my place?

Highly recommended!'

4 Naran: "Hai ganbarimasu!” ((solemn/firm tone))

'Yes, I will try!'

5 Oldokhbayar: ((laugh)) “Hai Mimasu!” ((solemn/firm tone)) gee:ch ganbarimasu

6

gedeg chini "khicheey" gesen ug baikhgui yu ((giggles))

'Yes, I will watch! You have to say! Ganbarimasu means "to try",

7 Dorj: [Khuuy:! Muu:sa:in samu:rainuu:daa:!]

8

"Duugui baitsgaa!" ((solemn/firm tone)) ((all three burst into laughter))

'Hey! Silly Samurais! Shut Up!'

9 Naran: $\quad$ I'm zero-headed in Japanese ((pause)) you know thatshuudee: tegeed yamar khel [deeriin?

'I'm zero-headed in Japanese ((pause)) you know that, don't you?

So what language is it in?' 
11 Oldokhbayar: Original] Japanese with no stupid translations by so called translators.

12 Naran: $\quad$ Tekh. Much better ((pause)) gehdee my Japanese is [zero shdee

'Yes. Much better but my Japanese is still zero'

13 Oldokhbayar: English subtitle] is on, OK? No lo:st in translation... ((giggles))...

In lines 1 to 8 , the speakers move in and around movie resources, as they role-play the Japanese movie, positioning themselves in a "kineikonic mode" (Mills 2011) or “filmic speaking” (Dovchin et al. 2015: 16) - importing and recycling various lines and quotations from the film. Whilst responding to her boyfriend's invitation to watch the classic Japanese movie, "Seven Samurai", by Akira Kurosawa, Naran (line 4) makes a parody of Samurai-sounding Japanese by employing "bushido" ['the way of the warrior'] style talking where people act like Samurai. She enacts solemn and firm tones, impersonating a male voice - "Hai ganbarimasu” ['OK, I will try']. Oldokhbayar, however, corrects Naran's use of Japanese, suggesting another version, “Hai mimasu!” ['OK, Let’s watch it!'], again parodying a bushidolike somber tone (line 5). This Samurai role-play is further interrupted by the third voice, Dorj, teasing them for acting like Samurais (line 7). Dorj playfully commands them to stop immediately, recycling a derogatory Mongolian reference to a Japanese person, “muusain samurainuudaa”, ['silly Japanese people']. The literal meaning of this derogatory reference can be rendered in English as something like "the senseless Samurais", although its meaning has been relocalized, referring to Japanese people in general. The relocalization of "Samurai" here is thus not interpreted as the "warrior-like" spirit associated with the cultural identification of "Samurai"; rather it is mobilized by the speakers through derogatory reference to the sense of Japaneseness in old Mongolia. The phrase is associated with the war between Japan and Mongolia in 1939, known as the battle of "Khalkhiin Gol", named after the river, which passes through the battlefield in Mongolia. The war was provoked by the undeclared Soviet-Japanese border conflict, engaging the Soviet Union, Mongolia and the Empire of Japan, ultimately resulting in defeat for the Japanese Army. Many old Mongolian movies that depict this war use frequent derogatory references against the Japanese army, their former enemy, including "muusain samurainuudaa".

The incorporation of Japanese resources here does not necessarily mean that the speakers claim to have fluent Japanese language skills. In fact, Naran repeatedly emphasizes, "I'm zero-headed in Japanese" (lines 9, 12). Naran here seeks to move beyond her current linguistic boundaries (she speaks English at an intermediate level), pushing her linguistic boundaries with 
other available semiotic resources. Meanwhile, the lines 9 to 13 halt the roleplaying, diverting the topic into a different facet, the lack of quality regarding foreign movie translations in Mongolia. Naran's use of "I'm zero-headed in Japanese" relocalizes a popular Mongolian slogan, "Noiliin nogoon teg" (something like "empty-headed" in English, literally translated as "nil green zero"), which is widely used by Mongolians to refer to someone who is lazy or not so hard working. Mongolian parents also tend to use this phrase frequently when berating their children for not doing their homework. This Mongolian sentiment is therefore captured in English, almost as if Naran is speaking Mongolian in English.

In a similar vein, in line 9, Naran Mongolianizes the English phrase "you know that" by adding the Mongolian suffix "-shuudee" [“don't you?"], creating a Mongolianized term "you know thatshuudee" ['you know that, don't you?']. Here, it no longer makes sense to recognize "thatshuudee-" as English, since it only achieves a meaningful communicative implication in combination with the Mongolian question tag suffix "-shuudee". The invention of "plantai" ['to have a plan'] in line 1 works in a similar way. The English stem "plan" plays a role here, but makes local meaning in the context of the Mongolian prepositional suffix “-tai” ['to have']. Since Naran's Japanese skill level is "zero", the speakers opt for English subtitles, avoiding Mongolian translations or Mongolian subtitles because they seem to get "lost in translation", implying the poor quality of Mongolian film translations.

This analysis shows that Naran and her boyfriend's linguascapes are produced from diverse linguistic and cultural resources saturated by their higher access to scapes. Naran is one of those post-socialist era, rural-to-city migrants who moved to UB back in 2004. She previously resided in Dalanzadgad, Umnugobi, a small rural town situated in the Gobi region, approximately $1,000 \mathrm{~km}$ away from the capital. Naran's parents are considered to be relatively well-off herders in the countryside (owning around 10 camels, 60 sheep, 10 horses and a few goats), and they operate a small agricultural business, in which they sell wool, meat and other dietary products to the local supermarkets. According to Naran, she started to feel "out-of-date" when she first arrived in UB, because of the negative ideoscapes surrounding rural people migrating to the city. There is often a sharp tension between the urban and rural populations in Mongolia. City dwellers tend to blame rural people for many of UB's social and environmental problems such as the chronic overcrowding created by the expansion of ger districts in the city, causing both severe traffic congestion and air pollution, the latter particularly during the winter months. Many urbanites also accuse the rural migrants of harming the city image with their anti-social behavior (spitting, littering, 
urinating in the street) and also mock them for popularizing "zokhioliin duu"1 ['country songs']. Many believe that urban people are "cool”, and rural people are "khuduunii khuusun mantuu", a derogatory reference to a rural person, literally meaning "stupid rural bun".

This tension affected Naran when she first moved to the city, causing her to make lifestyle changes in order for her to fit in. This included changing her appearance and the way she dresses: "I wanted to get rid of my tacky looking 'Made in China' platforms, as I was advised to wear Converse trainers instead because they were considered cool among my urban classmates" ${ }^{2}$; what music she listens to: "I needed to go to cool pop concerts instead of going to cheesy comedy shows. They would often laugh at me when I listened to 'zokhioliin duu", "People from UB would call their preferred music 'cool music' while they would label 'zokhioliin duu' as awkward and cheesy”.

Most importantly, her rural accent had become a problem: "When I opened my mouth, I started feeling the tension because I had this heavy rural accent. Urban people would speak these different languages while I stuck to my rural sounding Mongolian. I didn't want to sound like a 'stupid rural bun'. I wanted to be one of the proper modern members of the city". This account is also compatible with Blommaert and Dong's (2010: 377) reminder of a growing internal migration from rural areas to the cities in the context of China due to the country's economic boom. Such internal migration tends to reorder the linguascapes in the city, in which "certain accents mark a metropolitan, sophisticated identity, while others mark rural origins, low levels of education, and marginal social-economic status".

By incorporating these changes, Naran started to adjust to city life. Her position in the financescape is privileged, since her parents still send her money, which helps her to afford everything that comes with the expensive city lifestyle. Naran, however, adds that she worked hard to become part of the proper urban youth community: "I did my best to transform myself. I started looking at all different opportunities to change my old self. I didn't want to lock myself in my room. I wanted to go out and be there". This includes her socialization with mostly city classmates, and the student accommodation in the heart of the city: "I used to live

1 "Zokhioliin duu" ['country song'], a distinctive country style musical genre quite popular among the rural population, with monolingual lyrics often written in Mongolian, glorifying the love for homeland, mother's love, or the love for great horses, often performed by singers originating from rural areas.

2 Interviews with both Naran and Oldokhbayar were conducted on September 22, 2010, UB, Mongolia. All interviews used in this research were conducted in Mongolian, and translated into English by the researcher. 
with many students in my university dormitory. It is conveniently located in the city centre, and we have direct access to what the city has to offer. We do everything together: going out, clubbing, cinemas and concerts. So this networking and socializing helps me a lot to become familiar with every aspect of present-day UB”. Currently, she lives with her "city" boyfriend, Oldokhbayar, who plays an important role in forming her urban lifestyle: "When I first moved to UB, I was obsessed with Japanese TV drama and Tepei [referring to the main male character of the Japanese TV drama “Love Generation”, played by the Japanese pop idol Takuya Kimura]. He is the epitome of the perfect male for me. I only started dating Oldokhbayar because he used to look like Tepei”. Since she started dating Oldokhbayar, she has been heavily influenced by the way he talks, as he borrows heavily from English and Japanese in his daily linguistic repertoire. Naran's motivation for dating her boyfriend not only also illustrates the case of females from rural areas identifying males from urban areas as their romantic interest, but also resonates with ideas put forth in Takahashi's (2013) work on "akogare" among Japanese women and their desire to date Western/Anglo men as part of their plans to learn and use English in the world.

Here, we can see how Naran starts to transform through being in a relationship with her city-born boyfriend. Naran's boyfriend, Oldokhbayar, is an avid sportsman who has traveled to Japan occasionally to compete in international Taekwondo competitions. This nurtured an interest in Japanese culture. Since beginning his university studies, he claims to have started taking English classes seriously, although he also claims that his level of English is closely tied to watching movies in English. In terms of his heavy integration of English and Japanese in his linguascape, Oldokhbayar explains, "When I travel, there is a stereotype about Mongolia as backward or isolated. I'm rebellious in nature. I want to break that [stereotype]. Maybe I want to show them that young Mongolians are capable of speaking any language. We are not totally backward as others imagine. We are able to use English like everyone else". Here, Oldokhbayar redefines the established ideoscape about Mongolianness through his use of English, and perhaps Japanese, and it is in this interplay that Oldokhbayar claims a wider cosmopolitan identity to break the Mongolian stereotype.

Overall, Naran is involved in identity enactment, in which "one needs to create a persona (which may or may not be akin to one's embodied self) to project a sense of self to other" (Thomas 2007: 18). Here, Naran's identity was initially conditioned by the ideoscapes of what it means to be rural and urban. Her linguascape has started to transform as the space of contact has changed. This could only be achieved by her direct access to linguistic and cultural resources, saturated by her wealthy parents' financial advantages, her 
networking with city friends and her city boyfriend, her ample access to media/technoscapes, and her adjustment to varied urban versus rural ideoscapes. This further shows how a person's linguascape can be expanded and diversified through access to available resources. Naran seems to have adjusted to the linguistic norms of city speakers, so much so that she shows strikingly similar characteristics to those of her city counterparts. This section ultimately shows how a person's language practice cannot be judged on the sole basis of one's birthplace, but rather from uneven access to resources in the social scapes.

In the next set of extracts, I will look at the online linguascape of a privileged youth, Temir, a recent undergraduate from NUM, majoring in International Relations. Temir is multilingual, fluent in Mongolian, Kazakh (his background is Mongolian Kazakh), Russian and English; and with intermediate-level Chinese and Japanese. Most recently, he is a postgraduate student in Japan, studying for his Master's degree. Temir's position in the financescape is privileged as he was born and brought up in a financially privileged family in UB, his father being a renowned medical consultant in the largest cancer centre in Mongolia. Temir went to one of the most prestigious high schools in Mongolia with students whose families could afford a comfortable lifestyle.

Extract 2

FB text: 1. Temir:

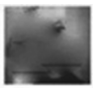

9 November $2014 \cdot 24$

Time is always short for those who need it ntr gej megee I

Like Comment $\Rightarrow$ Share

4 people like this.

2. Bileg:

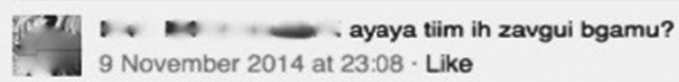

3.Temir:

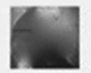

- Zavgui setgel sanaa tavgui :-:

9 November 2014 at 23:15 - Like

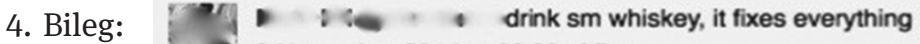

9 November 2014 at 23:20 - Like

5. Temir:

- In n Nooooo it ruins everything

9 November 2014 at 23:24 - Like

6. Bileg: hahaha spoken like a true expert

9 November 2014 at 23:26 - Like - B1 
Translation

1. Temir:

Time is always short for those who need it (as if I'm going to manage it properly)

2. Bileg:

ayaya are you that busy?

3. Temir:

Busy and moody

4. Bileg:

drink sm whiskey, it fixes everything

5. Temir:

Noooo it ruins everything

6. Bileg:

hahaha spoken like a true expert

One of Temir's most frequent linguistic resources integrated in his FB is a heavy incorporation of English. He uses a large amount of English oriented resources, including multimodal repertoires, links, videos, proverbs and images. Temir also occasionally uses sentences in exclusive or partial English to interact with his FB friends. He learned English at high school, and specialized in English at NUM while studying International Relations. However, Temir prefers to explain his proficiency in English from the perspective of his direct access to mediascape and technoscape: "To be honest, I mostly learned English from Cartoon TV and English news”. In terms of his linguistic choice on FB, he says: "I use English most of the time on my FB because sometimes or most of the time it is easy to express things in English. The nuance is there and everyone understands English so you get more responses" (Facebook Interview, October 29, 2014).

In Extract 2, Temir incorporates the English proverb "Time is always short for those who need it", which is accompanied by the Mongolian phrase, "ntr gej megeel" (line 1). It is common for transnational online users to be engaged with multiple orthographic options, including one of the most common practices of shortening or abbreviating certain phrases and terms (Dovchin 2015; Sultana et al. 2013). To this end, by omitting the vowel " $e$ " from "ene ter", online users in Mongolia widely use "ntr", meaning "so on" or "et cetera". However, in this particular context, "ntr" is combined with "gej megeel" - a colloquial Mongolian phrase meaning "as if". Together the phrase " $n t r$ gej megeel" can be roughly translated into English as "as if it is going to actually happen". Here, Temir tries to express the meaning that he is a busy person who is always short of time through the incorporation of the English proverb, yet he is adding a sarcastic and playful tone to his post by incorporating a colloquial Mongolian phrase implying that he is actually not going to manage his time wisely because he is in fact poor at time management. 
His FB friend, Bilgee, starts commenting on Temir's post (line 2). The boys initially start interacting in Mongolian when Bilgee teases him for declaring his busy schedule publicly on FB, using "ayaya" - a paralinguistic sign used extensively amongst Mongolian youth when they tease each other (line 2); Temir reiterates that he is not only busy but also moody, using the emoticon of a "poking tongue" to signal that he is being silly and childish for being "moody" (line 3). Meanwhile, it is also relevant to note here that young adults with radically different socioeconomic experiences are generally not friends in other contexts, as the affluent youth tend to hang out with other affluent counterparts and vice versa. In fact, many of Temir's FB friends are transnationally mobile and are considerably more privileged than their peers. This observation can be seen in the next set of interactions when Bilgee uses English extensively in a similar vein to Temir (lines 4, 5, 6). It is clear from the interaction that the boys are at ease when they use English, and they seem to creatively negotiate the place of English in their interaction, while teasing and mocking each other. Using English exclusively, Bilgee teases Temir that he should drink whiskey if he is moody (line 4) and that Temir knows about the effect of whiskey like a true whiskey expert (line 6), while Temir insists that whiskey ruins everything (line 5). Note that Bilgee uses a shortened version of "some", "sm" - a common online practice (line 4) - while Telnar expresses his objection by lengthening the vowel for "no" to intensify his tone (line 5).

\section{Extract 3}

FB text

1. Temir:

\section{Erdene:}

3. Temir:

4. Watanabe:

5. Zuchi:

6. Temir:

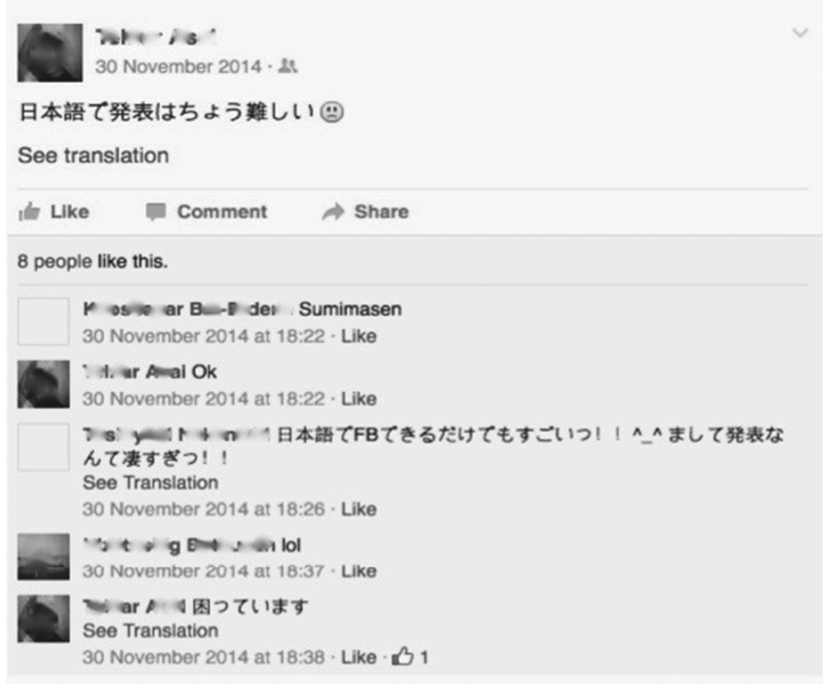


Translation

1. Temir: Presenting in Japanese is extremely difficult

2. Erdene: Sorry

3. Temir: Ok

4. Watanabe: It is even amazing that you can "do" FB in Japanese. Let alone presentation (in Japanese).

5. Zuchi: lol

6. Temir: I am struggling

It is a common practice for Temir to move beyond English resources, importing varied other multilingual (Japanese and Chinese) repertoires to his daily FB activities. Japanese is one of the most frequented resources in his linguascape. In Extract 3, Temir's FB linguascape moves in and out of Japanese and English linguistic resources. This should be understood through Temir's current physical location, as he is based in Japan doing his postgraduate degree. The Japanese posts in Extract 3 are written in very typical Japanese youth language, with correct grammar. Temir complains that doing presentations in Japanese is difficult for him, accompanied by the emoticon of a sad/annoyed face (line 1).

Meanwhile, his Japanese FB post starts getting responses from his Mongolian and Japanese friends, showing Temir's wider transnational network due to his active mobility in the ethnoscape. Temir's FB friends' list consists of varied people around the world. In line 2, Erdene shows emotional support to Temir, saying "sumimasen” ['Sorry!'], using transliterated Roman Japanese, indicating the meaning of "sorry to hear that". Telnar accepts his friends' support by simply saying, "Ok” (line 3). In line 5, Zuchi says "lol”, the acronym for "laughing out loud" to sympathize with Temir's effort of learning Japanese. Here, "lol" indicates a meaning akin to "yes, I have to laugh hard because learning Japanese is a joke [meaning learning Japanese is difficult]". In line 4, his Japanese friend Watanabe compliments Temir's Japanese skill as being so good that he is not only presenting but also "Facebooking" in Japanese, to which Temir replies in Japanese that he is struggling (line 6). This smooth interaction between Temir and Watanabe exclusively in Japanese shows Temir's high access to Japanese linguistic resources and his privileged transnational networking in the ethnoscape. 


\section{Extract 4}

FB text

1. Temir:

2. Dorj:

3. Temir:

4. Andy:

5. Temir:
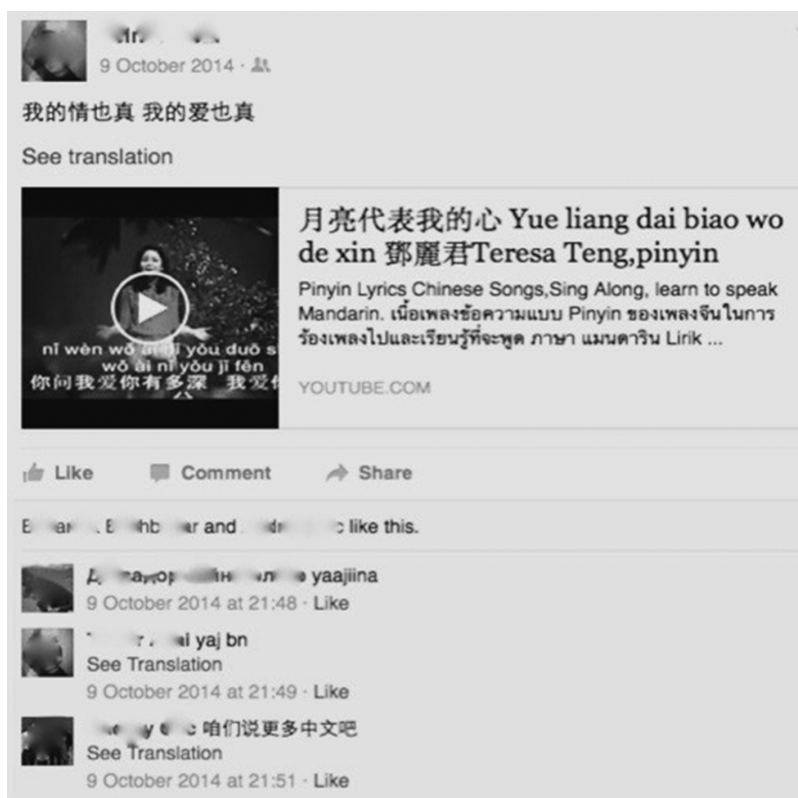

ar 说什么?

See Translation

9 October 2014 at 21:53 - Like

Translation

1. Temir: My soul (heart) is real, my love is real

2. Dorj: What is happening?

3. Temir: What [do you mean what is happening]?

4. Andy: Let's say something more in Chinese, shall we?

5. Temir: Say what?

In addition to Japanese, Temir's linguascape is created by the integration of Chinese resources. In Mongolia, Chinese is generally considered to be one of the hardest languages to learn. Nevertheless, Temir's import of Chinese indicates his access to Chinese language and culture, which mainly needs to be understood in the context of his experience of living for a year in Beijing. In Extract 4, Temir updates his FB with the Chinese music video hyperlink “我的情也真 我的爱 也真” ['My soul (heart) is real, my love is real']. Temir refers to this song as "one of the most popular Chinese songs in the whole world" (Facebook Interview, 
October 29, 2014). Clearly, one of his FB friends, Dorj, does not seem to understand what Temir has just posted in Chinese and shows his surprise by asking Temir what exactly is happening, using transliterated Roman Mongolian, "yaajiina” (line 2). Temir responds "yaj bn?”, referring to the message "what do you mean what is happening?", or to put it differently, "why are you so surprised about it?" (line 3). This means that Temir wants to show that it is perfectly normal for him to post something in Chinese, and there is nothing to be surprised about. It also indicates Temir's more advantaged position in the linguascape than his friend Dorj, who seems to be illiterate in Chinese. In lines 4 and 5, Temir's Chinese skill is reiterated through his interaction with his transnational and non-Mongolian FB interlocutor Andy. Both Temir and Andy start using Chinese as a lingua franca despite their non-Chinese background, displaying their privileged exposure to Chinese resources.

Overall, Temir's FB linguascape is created by the mixture of varied linguistic and cultural resources, suggesting his advantaged and affluent access to other social scapes. While his active engagement with FB shows his direct access to media/technoscape, his efficient use of Chinese, English and Japanese, using complex icons and small characters with Japanese kanji or Chinese characters, shows his active mobility in the linguascape. His interaction with his friends all over the world marks his affluent mobility in the ethnoscape. Because of his privileged lifestyle, his linguistic and cultural diversity becomes more mobile and higher than that of those who are located in the marginal positions.

\subsection{Uneven resources in underprivileged youth linguascapes}

In this sub-section, I offer linguistic analyses of the online and offline linguascapes of young adults from an underprivileged background in Mongolia, who have less and lower mobility within the movement of scapes. In Extract 5 below, I look at the linguascapes of Battsetseg and her classmates, engaged in a casual face-to-face conversation. The interlocution occurs at the end of one of our linguistic ethnographic research sessions, in which I addressed my research participants with the intention of collecting their Facebook or email addresses for potential future correspondence. Two speakers are involved in this conversation, although I will specifically focus on Battsetseg's account. Battsetseg (aged 18 years, a first year math student at NUM) was admitted to NUM after winning the high school "math Olympiad", which allowed her to study at NUM on a full government scholarship. 


\section{Extract 5}

Language guide: Mongolian - regular font; English - italics; Russian underlined italics

1 Researcher: $\quad$...Chi Facebookgui yumuu? Nemekh kheregtei [bna. 'Don't you have Facebook? I need to add you.'

2. Battsetseg: No:shuudee:!] Bi ter Pee:sbookiig yostoi meddeggui. 'Kind of no, I have no idea what FB is.' Manaikhan “Pee:sbook Pee:sbook!” 'Aaaaaaaaaa:!' ((screaming and impersonating loud, high-pitched female voice))

4 geel amia ugchikh geel baidiin ((loud laughter)) 'My classmates just die for it! "Facebook Facebook!" “Aaaaaaaaa!!”,

5 Researcher: Bi zaaj ugukhuu? Suuld kholbootoi baikh kheregtei baina. 'I can teach you, if you want? I need to contact you later'.

6 Battsetseg: ((Eeeeee::!)) Yos:toi medekhguidee ((pause)). Bi gertee 7 enternaatgui bolokhoor yostoi goshin yum bolokh baikhaa. 'I'm not sure about that. I don't have Internet at home, so it would be hard'.

8 Researcher: Za za uuruu 1 med. Emailee teguul? Chatand khir ordog yum? 'Well, it's up to you then. How about your email address then? Do you chat sometimes?'

9 Battsetseg: ((Aaa:::n)) Khaayaa shalganaa: bas ((giggles)), eemelgu hun gej yu

10

baihav ((giggles)). Kharin chatad bol orokhguieee zav ch baikhgui

orood baikh confuu:tar ni ch baikhgui ((deep sigh)).

'Sometimes. Everyone has emails, come on! I don't chat though, I don't have time and computer'.

12 Sunderiya: Manai Battsetseg aimar zavguie:. Aimar khol avtobusaar yavdiin

[khuurkhii:!

'Our Battsetseg is really busy. Poor her! She travels by bus long distance'.

14 Battsetseg: Udurt avtobusaar] yavna gedeg chini temtselshuudee ene khotod.

"G-khoroolold" amidarna gedeg chini udur tutmiin temtselshuudee!...

'It is such a big struggle to travel daily by bus in this city. Living in the "G-(ger) district” is a daily struggle....' 
Battsetseg's linguascape is produced by English- and Russian-oriented linguistic resources embedded within prevalent Mongolian. It is, however, important to note that she has very limited access to these languages. As for her use of English, it needs to be firstly understood in terms of technoscape - Internet genre terms in her Mongolian dominated speech ["Peesbookiig”, "enternaatgui”, "eemelgu”, “chatad", “confuter"] parodying widely popular "Internetized Mongolian terms" (Dovchin 2016a) - that combine Internet stem words with the Mongolian linguistic resources (lines 2, 3, 7, 8, 9, 10, 11). It is worth noting that these terms are not only restricted to young speakers, but also commonly used across the middle-aged population. In this particular context, however, these terms are affected by Battsetseg's heavy "regional dialect", which is viewed as a "rural speech style" in UB. For example, when she says "Peespuukiig" (lines 2, 3), she refers to "Facebookiig", in which an Internet stem "Facebook" is mixed with the Mongolian suffix modifier "-iig”, creating the term "Facebookiig" ['Facebook is']. Battsetseg transforms "Facebookiig” into "Peespuukiig”, where she pronounces initial " $[F]$ ” as " $[P]$ ”; middle “ $[b]$ ” as “[$[p]$ ”; middle diphthong "[ei]" as enunciated "[e:]". Similarly, when she says "confuter", she means "computer", where the middle " $[\mathrm{m}]$ " is replaced by " $[n]$ " and middle " $[p]$ " pronounced as "[f]". The terms, "enternaatgui" ['without Internet'] (line 7) and "eemelgu" ['without email'] (line 9) are similar, in which "Internetgui", the combination between Mongolian suffix preposition "-gui" ['without'] and English stem, "Internet", is transformed as "enternaatgui"; "emailgui" ("email" + "gui" = "emailgui") is pronounced as "eemelgu". Here, the combination between Internet semiotic resources and Mongolian linguistic features is so seamlessly transformed, it is almost impossible to classify "eemel" ['email'] or "enternaat" ['Internet'] as English. Battsetseg's style of pronouncing stop consonants and diphthongs is often regarded as "country style" within the ideoscape of many city dwellers in Mongolia, who criticize rural people for distorting foreign-originated Mongolian words. Her classmates, for example, informed me that Battsetseg is often ridiculed for her heavy rural accent. The accent of this speaker clearly illustrates the very clear rural accent observed by city speakers.

Secondly, Battsetseg transforms the English stem "no" into Mongolian by integrating it with the Mongolian suffix "-shuudee" ['-is'], creating "noshuudee", meaning "no!" in Mongolian (line 2). "Noshuudee” should not be understood as a novel expression here, since the term is generally very popular across young Mongolians. On many occasions, I have witnessed the way young Mongolians opt to use "noshuudee" during the course of my (n)ethnographic participant observation stage. 
Battsetseg also uses the English alphabet, "G", referring to "G-khoroolol" ['ger district'], pronouncing the alphabet distinctively in English "[dzii]" (lines $14,15)$. Ger district youth often refer to ger district as "G-khoroolol" to make it sound more stylish, and they proudly call themselves as "G-giikhen", meaning "from ger district". The youth population of city centres are not familiar at all with these terms, as they are almost exclusively used within the circle of ger district youngsters.

Further, the speaker uses a Russianized Mongolian term, "avtobusaar" ['by bus'] (lines 12, 14), with the Russian stem word “автобус" [avtobus; 'bus'] mixed with the Mongolian postposition suffix "-aar" ['by']. This term, however, has been localized in Mongolia since the Soviet era, and is commonly used as part of the local vocabulary.

Linguistic creativity and playfulness is also present. The speaker, for example, parodies her friends who spend so much time on Facebook (line 3), by uttering "Peesbook, peesbook!" [referring to 'Facebook'] using a loud, highpitched noise to sound like a female voice, followed by the loud exclamation “aaaaaaaaaa”, playfully impersonating screaming girls.

Overall, Battsetseg's linguascape consists of rather thin lines of resources compared to the examples of privileged counterparts discussed in the previous examples. While the linguascapes of privileged speakers in the previous extract were constructed by the heavy incorporation of English, Chinese and Japanese, Battsetseg's linguascape is created mainly by bits and pieces of English, which are already considered as the linguistic norms in the sociolinguistic circumstances of Mongolia (e. g. some already widely used Internet terms). This can be explained through her restricted access to scapes. Battsetseg is originally from Bulgan province, although her family moved to UB in 2006 after losing all their livestock in "zud" - a heavy snow blizzard that ruins the grassland for livestock. Her family has been living in the "Dambadarjaa" ger district of UB since their move. The relocation from the rural area has not been smooth, and life in UB is hard for Battsetseg: “We don't eat twice, but we don't eat nothing”. Her family's marginal position in the financescape prevents Battsetseg from having higher mobility within media/technoscape, as she neither has a computer nor Internet connection at home. She is learning "Basic English" at university twice a week as a core subject, yet it is not enough for her to use English on a daily basis. Her father is still struggling to find a proper job in UB, whilst her mother is working part-time as a cleaner in the local school. Her position in the ethnoscape is somewhat restricted since she has never traveled abroad. Battsetseg has admitted that she skips her classes on many occasions due to her long journey from ger district to the city by public transport, which is often gridlocked by severe traffic jams in UB. 
On the superficial level, Battsetseg's linguascape can perhaps be interpreted as "diverse" because of her import of English and Russian in her Mongoliandominated speech. At another, deeper level, however, her linguascape may also be interpreted as "less diverse", when compared with the linguascapes of other privileged speakers. However, Battsetseg also uses certain unconventional terms (e. g. "G-khoroolol”), which are not necessarily widely known within the culture of affluent youth, suggesting that linguistic creativity is not only restricted to affluent youth. This means that certain linguistic resources circulating around ger district are not necessarily available within the circle of city centre youngsters and vice versa. Hence, the flows of linguistic resources are uneven.

In the next set of extracts below, I will look at the linguascape of underprivileged youth from the perspective of the online context. Naidan (18, male) is an undergraduate student at NUM who was born and raised in Yarmag, on the outskirts of UB, where he lives in the ger district. He is studying at NUM, because he wants to gain a higher education, and is currently reliant on the government's higher education loan system. He is representative of a financially marginalized group in Mongolia. Naidan's mother is a single parent, who is raising five more children; Naidan is the eldest.

\section{Extract 6}

FB text

1. Naidan:

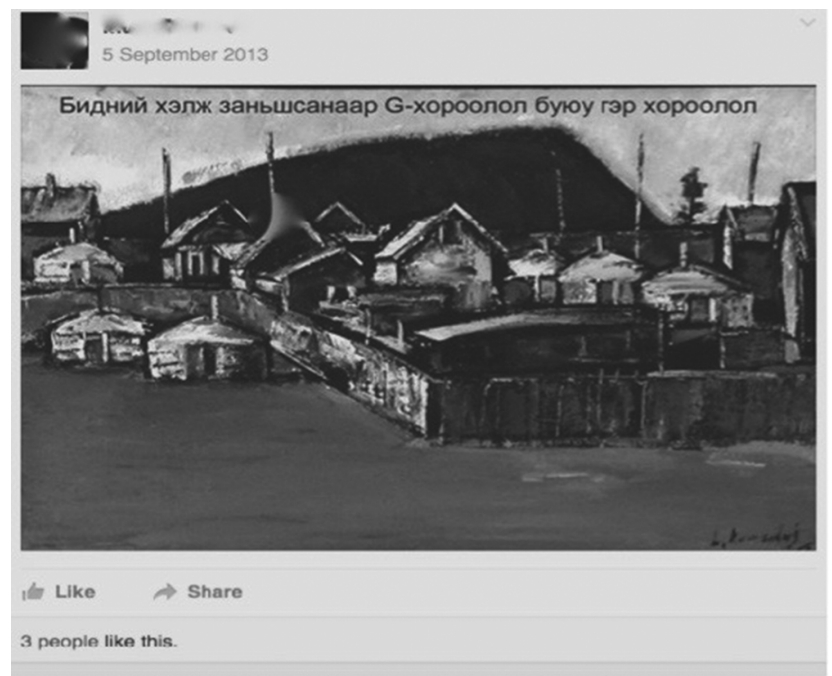

Translation

1. Naidan: 'As we are accustomed to say: G-district or ger district'. 
Naidan's FB linguascape is better understood through his limited access to linguistic and cultural resources. Naidan is inactive most of the time on his Facebook, frequenting it once or twice fortnightly or monthly. His presence on FB is restricted and he has less access to media/technoscape: "I have a very busy lifestyle. I have too many daily chores to deal with and I don't even have time to watch TV" (Interview, September 30, 2010, UB, Mongolia). Naidan's busy lifestyle is mostly associated with his ger district way of life, involving numerous subsistence activities such as collecting fresh water from water trucks, picking up coal and other fuel for heating, looking after his siblings and so on. It is also important to note that because of Naidan's marginalized position in the finance/ ethnoscapes, he has neither traveled abroad nor does he have many transnational friends.

His FB linguascapes are often created by varied images and photos of ger districts with everyday activities, written in predominantly standard Cyrillic Mongolian. For example, in Extract 6, Naidan posts an image of ger district, titled in Cyrillic Mongolian with the English alphabet " $G$-" incorporated: “Бидний хэлж заньшсанаар G-хороолол буюу гэр хороолол” [“As we are accustomed to say: G-district or ger district']. Through this post Naidan seeks to show how proud he is to be living in the ger district despite its harsh living conditions. Like Battsetseg, who also imports “ $G$-хороолол” into her offline linguascape in the previous sub-section, Naidan integrates "G-хороолол" in his online linguascape. This shows that the phrase is quite popular amongst ger district youth speakers, though almost never heard amongst city youth speakers.

It is also evident that Naidan's FB posts receive neither multiple " $F B$ comments" nor "likes", despite Naidan having around 90 FB friends. In fact, having fewer than 100 friends is considered to be not so many in FB terms. Hence, the poster is perceived as not so "popular" amongst young Mongolian FB users. Naidan's FB post in Extract 6 has not received any " $F B$ comments" and only three "likes". This means that Naidan's FB friends seem to be less active on FB compared to the affluent youth members described in the previous discussions. Perhaps, just like Naidan, his FB friends have limited access to and a less mobile position in the techno/mediascape, because less advantaged youth members tend to hang out mainly with each other. 


\section{Extract 7}

FB text

1. Naidan:

2. Anand:

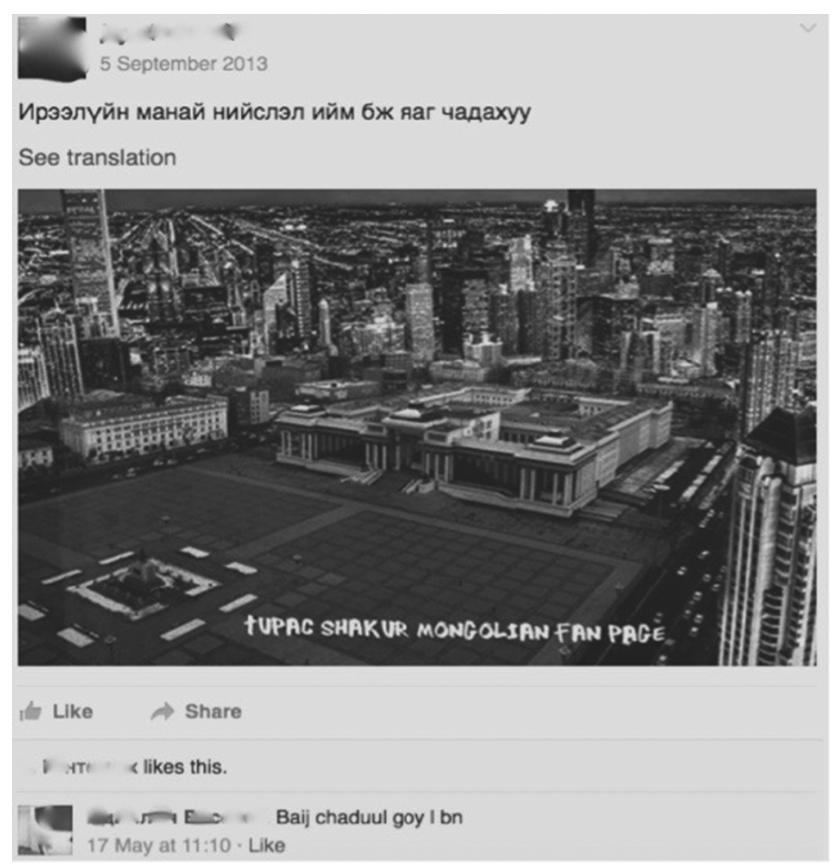

Translation

1. Naidan: 'Can our capital city look like this in the future?'

2. Anand: 'It would be nice [if it looks like this]'

Naidan's FB linguascape is created not only in Cyrillic Mongolian, but occasionally incorporates English oriented resources. In Extract 7, Naidan predominantly uses Cyrillic Mongolian, in which he posts a rhetorical question about whether Ulaanbaatar, the capital city of Mongolia, could look like the photo of a city with gleaming skyscrapers in the near future. It should be noted, however, that his Cyrillic Mongolian post contains the shortened version of "baij”, “bj” ['to be'], omitting the middle vowel "ai", in a very similar vein to Temir's FB friends, who also shorten English words. Here, Naidan's FB post is further elaborated by the English linguistic resources, where his posted image is expanded by an imprint of a sign in English, "TUPAC SHAKUR MONGOLIAN FAN PAGE”. This English sign not only portrays Naidan as a loyal fan of American Hip Hop artist $2 \mathrm{Pac}$; it also reflects his determination to publicize his favorite Mongolian Facebook page dedicated to the late American rapper. 
Another instance of English oriented resources in this FB post is illustrated through the comment of Naidan's FB friend Anand. As discussed earlier, the majority of Naidan's FB posts receive hardly any "comments" and "likes" from his FB friends. Yet for this particular post, he has received three "likes" and one “comment". The only feature that sets this particular comment apart, however, is that it uses transliterated Roman Mongolian instead of standard Cyrillic Mongolian. Yet again, using transliterated Roman Mongolian is neither creative nor eccentric, as it is considered by many young Mongolians to be one of the most mundane online local language practices due to the ready accessibility and convenience of the keyboard (i. e., some computers in Mongolia lack Cyrillic Mongolian fonts) (see also Dovchin 2016a).

\section{Extract 8}

FB text

1. Naidan:

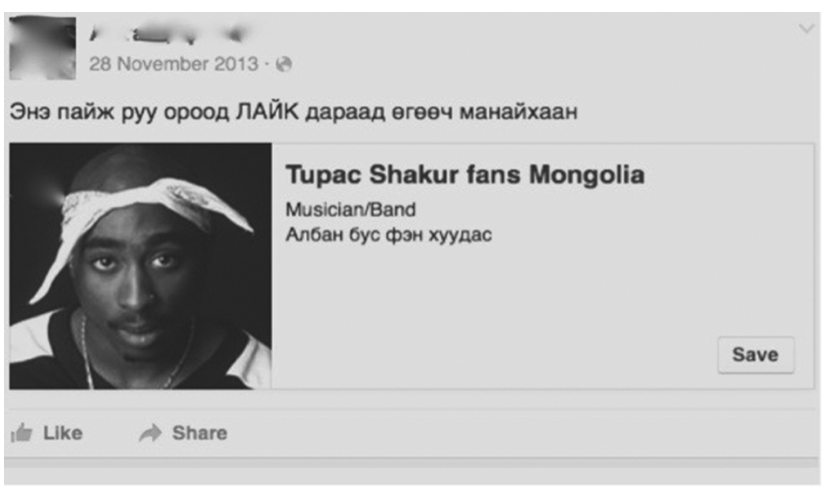

Translation

1. Naidan:

'Folks. Can you please go into this page and click the like buttons?'

Occasionally, Naidan's FB linguascape is constructed by the mixture of English and Mongolian. However, the use of English should be better understood as part of the local language rather than as English. The kind of English resources he uses are so ordinary and commonplace that they are almost considered part of Mongolian vocabulary. By contrast, resources employed by privileged youth may appear quite unusual and novel to the eyes of ordinary Mongolians. In Extract 8, Naidan posts a link to the fan page of his favourite hip-hop artist, Tupac Shakur, accompanied by Cyrillic Mongolian, “Энэ пайж руу ороод ЛАЙК дараад өгөөч манайхаан”. In a similar vein to the previous Extract 6, this FB post has not received any likes or comments from his FB friends, indicating the 
“inactive” position of Naidan's FB peers. Also, despite its dominant incorporation of Cyrillic Mongolian, Naidan's post is partially created by the combination of "FB semiotic resources integrated with Mongolian" - "Facebookized Mongolian" (Dovchin 2016a) - in which he Mongolianizes the Facebook default feature "like" button by not only spelling it in Cyrillic Mongolian according to its pronunciation, but also transforming it into Capitalized Cyrillic Mongolian (“ЛАЙК”); and by spelling “page" in Cyrillic Mongolian according to its pronunciation as “nаŭж”. Facebook default features are so deeply Mongolianized that they are no longer recognized as Facebook features.

One may argue that the incorporation of these "Facebookized Mongolian" phrases in Naidan's FB posts gives the impression that his linguascape is creatively mixed with English. However, in Naidan's case, this particular FB post is simply normal local linguistic activity, where the particular FB user is more regulated by FB's default linguistic features (e. g. "like", "share", "comment" buttons), used by thousands, if not millions, of other Mongolian FB consumers. So much so that some of these FB default features are deeply relocalized and used as part of local language amongst FB users in Mongolia (e. g. “Minii zurgiig 'like’ khiigeechee!” ['Why don’t you 'like' my photo?'], “Minii zurgiig bitgii 'tag'laaraai!” ['Don't tag my photo, please!']).

Overall, it can be argued that Naidan's FB linguascape is produced by the combination of predominantly standard Cyrillic Mongolian mixed with some English oriented linguistic and cultural resources (e.g. Facebookized Mongolian, transliterated Roman Mongolian, genre specific signs such as Tupac Shakur's fan page) that are less complex and more "archaic" than his privileged counterparts. The use of English resources integrated within Naidan's linguascape is rather localized and extensively practiced as part of local language amongst Mongolian online users.

\section{Conclusion: Understanding linguascape as fundamental but uneven}

Drawing on offline and online casual interactions in the context of young adults in Mongolia, this article offers two important implications in understanding youth linguascapes in current globalization. First, youth linguascapes in Mongolia are fundamentally miscellaneous, produced by the colliding and intersecting transnational flows of linguistic, cultural, financial, ideological and technological resources. Particularly, the linguascapes are mixed with bits 
and pieces of English, Japanese, Russian and Chinese linguistic resources embedded within Mongolian. These linguistic resources are presented in varied forms, styles, genres and repertories: English, for example, is localized when it is used as Romanized/transliterated Mongolian, Facebookized Mongolian and Internetized Mongolian; Japanese is used in the form of parody with respect to movie genres; or Chinese is used in the form of song lyrics.

Meanwhile, these mobile linguistic resources embedded within linguascapes are not distributed evenly throughout these speakers. The resources are localized in an uneven or overlapping manner that needs to be understood in relation to the speakers' access to available resources and their locatedness around the scapes. The majority of privileged speakers, who seem to relish higher mobility within the scapes, are creating complex linguascapes that go beyond their linguistic and cultural boundaries. They are more likely to have greater and more direct access to the resources within scapes compared to most of their underprivileged counterparts. They are privileged enough to intensify the diversity, creativity and variety of linguistic resources they are involved with. By contrast, youth with lower mobility in the scapes seem to create the linguascapes with less fluidity and lower mobility, which prevent them from fully participating within the multiple activities compared with their advantaged counterparts. Most of them have not traveled across borders in the ethnoscape, lack sufficient time and access to media/technoscape, are outdated in the ideoscape and are marginalized in the financescape.

Second, although the distribution of resources is understood as an uneven process, which may demonstrate the characteristics of inequality and disparity, it is nevertheless observed through its fluidity - the flows of resources across the speakers. On the one hand, linguistic and cultural resources can be interpreted as open to all, since the speakers are engaged with the complex process of exploiting available resources. The idea of "available resources", on the other hand, is crucial here, because although the speakers may be restricted to certain resources due to their locatedness in the scapes, they are nevertheless involved with other available communicative resources at their disposal, circulating across time and space. A member of underprivileged youth, for example, may experience inadequate access to resources but may nevertheless diversify their language practice across other available resources in the context of interaction (e. g. "G-khoroolol"), which comes hand in hand with other linguistic resources. Likewise, a member of privileged youth may be perceived as a highly skilled bi/ multilingual speaker, although their language practice is expanded and transformed by exposure and the movement of other resources. In other words, the linguascapes of these speakers are produced by an "uneven" (the resources used 
by affluent youth are not available within underprivileged youth and vice versa) and "overlapping" (both affluent and underprivileged youth use the same Internet oriented terms) disjuncture of moving linguistic and semiotic resources, which needs to be understood through speakers' access to communicative resources.

Acknowledgements: I gratefully acknowledge the intellectual guidance of Professor Alastair Pennycook, my PhD supervisor. I would also like to thank the editor Ingrid Piller and two anonymous reviewers whose insights added value to this article. I wish to dedicate this article to the loving memory of my mother Erdenechimeg Perliijantsan.

\section{Appendix}

\section{Transcript Convention}

: $\quad$ Lengthened segments/an extension of the sound or syllable

... Texts omitted

((...)) Reporting non-verbal statements and gestures

[ The point where overlapping talk and/or gesture starts

] The point where overlapping talk and/or gesture ends

\section{References}

Androutsopoulos, Jannis. 2006. Introduction: Sociolinguistics and computer-mediated communication. Journal of Sociolinguistics 10(4). 419-438.

Appadurai, Arjun. 1996. Modernity at large: Cultural dimensions of globalization. Minneapolis, MN: University of Minnesota Press.

Appadurai, Arjun. 2001. Grassroots globalization and the research imagination. In Arjun Appadurai (ed.), Globalization, 1-21. Durham: Duke University Press.

Appadurai, Arjun. 2006. Disjuncture and difference in the global cultural economy. In Meenakshi Gigi Durham \& Douglas Kellner (eds.), The media and cultural studies: Keyworks, 584-604. Malden, MA: Blackwell Publishing.

Beery, Kelli. 2004. English in the linguistic landscape of Mongolia: Indices of language spread and language competition. West Lafayette, IN: Purdue University PhD thesis.

Billé, Franck. 2010. Sounds and scripts of modernity: Language ideologies and practices in contemporary Mongolia. Inner Asia 12(2). 231-252.

Blommaert, Jan. 2010. The sociolinguistics of globalization. Cambridge: Cambridge University Press. 
Blommaert, Jan \& Ad Backus. 2013. Superdiverse repertoires and the individual. In Ingrid de Saint-Georges \& Jean-Jacques Weber (eds), Multilingualism and multimodality, 11-32. Rotterdam: SensePublishers.

Blommaert, Jan \& Jie Dong. 2010. Language and movement in space. In Nikolas Coupland (ed.), The handbook of language and globalization, 366-385. West Sussex: Wiley-Blackwell.

Cohen, Roger. 2004. The current status of English education in Mongolia. Asian EFL Journal 6(4). 1-21.

de Bres, Julia. 2015. Introduction: Language policies on social network sites. Language Policy 14(4). 309-314.

Dovchin, Sender. 2011. Performing identity through language: The local practices of urban youth populations in post-socialist Mongolia. Inner Asia 13(2). 315-333.

Dovchin, Sender. 2015. Language, multiple authenticities and social media: The online language practices of university students in Mongolia. Journal of Sociolinguistics 19(4). 437-459.

Dovchin, Sender. 2016a. The ordinariness of youth linguascapes in Mongolia. International Journal of Multilingualism. http://dx.doi.org/10.1080/14790718.2016.1155592 (accessed 15 April 2016).

Dovchin, Sender. 2016b. The translocal English in the linguascape of popular music in Mongolia. World Englishes. http://dx.doi.org/10.1111/weng.12189 (accessed 17 May 2016).

Dovchin, Sender, Shaila Sultana \& Alastair Pennycook. 2015. Relocalizing the translingual practices of young adults in Mongolia and Bangladesh. Translation and Translanguaging in Multilingual Contexts 1(1). 4-26.

Dovchin, Sender, Shaila Sultana \& Alastair Pennycook. 2016. Unequal translingual Englishes in the Asian peripheries. Asian Englishes. http://dx.doi.org/10.1080/13488678.2016. 1171673 (accessed 27 May 2016).

Heller, Monica. 1992. The politics of codeswitching and language choice. Journal of Multilingual \& Multicultural Development 13(1-2). 123-142.

Heller, Monica. 2007. Bilingualism as ideology and practice. In Monica Heller (ed.), Bilingualism: A social approach, 1-22. New York: Palgrave Macmillan.

Heller, Monica. 2010. Language as resource in the globalized new economy. In Nikolas Coupland (ed.), The handbook of language and globalization, 349-365. West Sussex: Wiley-Blackwell.

Higgins, Christina. 2009. From Da Bomb to Bomba: Global hip hop nation language in Tanzania. In H. Samy Alim, Awad Ibrahim, and Alastair Pennycook, (eds.), Global linguistic flows: Hip hop cultures, youth identities, and the politics of language, 95-113. New York: Routledge.

Higgins, Christina. 2013. When local and global scapes collide: Reterritorializing English in East Africa. In Rani Rubdy \& Lubni Alsagoff (eds.), Language choice and linguistic and cultural hybridity at the global-local interface, 17-40. Bristol: Multilingual Matters.

Jaworski, Adam, Crispin Thurlow, Sarah Lawson \& Virpi Ylänne-McEwen. 2003. The uses and representations of local languages in tourist destinations: A view from British TV holiday programmes. Language Awareness 12(1). 5-29.

Kozinets, Robert. 2002. The field behind the screen: Using netnography for marketing research in online communities. Journal of Marketing Research 39(1). 61-72.

Kozinets, Robert. 2015. Netnography. The International Encyclopedia of Digital Communication and Society. 1-8. 
Leppänen, Sirpa, Anne Pitkänen-Huhta, Arja Piirainen-Marsh, Tarja Nikula \& Saija Peuronen. 2009. Young people's translocal new media uses: A multiperspective analysis of language choice and heteroglossia. Journal of Computer-Mediated Communication 14(4). 1080-1107.

Leppänen, Sirpa, Janus Spindler Møller, Thomas Rørbeck Nørreby, Andreas Stæhr \& Samu Kytölä. 2015. Authenticity, normativity and social media. Discourse, Context \& Media 8. 1-5.

Martin-Jones, Marilyn \& Sheena Gardner. 2012. Introduction: Multilingualism, discourse, and ethnography. In Sheena Gardner \& Marilyn Martin-Jones (eds.), Multilingualism, discourse, and ethnography, 1-19. New York: Routledge.

Mesthrie, Rajend. 2015. Towards a distributed sociolinguistics of postcolonial multilingual societies. In Dick Smakman \& Patrick Heinrich (eds.), Globalising sociolinguistics: Challenging and expanding theory, 80-91. London: Routledge.

Mills, Kathy. 2011. "Now I know their secrets": Kineikonic texts in the literacy classroom. Australian Journal of Language and Literacy 34(1). 24-37.

Mongolian Economy Journal. 2013. Middle class:Dowe haveonein Mongolia?. http://mongolia neconomy.mn/en/i/3535 (accessed 11 December 2013).

Pennycook, Alastair. 2003. Global Englishes, Rip Slyme and performativity. Journal of Sociolinguistics 7(4). 513-533.

Pennycook, Alastair. 2007. Global Englishes and transcultural flows. London: Routledge.

Pietikainen, Sari \& Helen Kelly-Holmes. 2013. Multilingualism and the periphery. In Sari Pietikainen \& Helen Kelly-Holmes (eds.), Multilingualism and the periphery. 1-17. New York: Oxford University Press.

Rampton, Ben, Karin Tusting, Janet Maybin, Richard Barwell, Angela Creese \& Vally Lytra. 2004. UK linguistic ethnography: A discussion paper. www.ling-ethnog.org.uk.

Rantanen, Terhi. 2006. A man behind scapes: An interview with Arjun Appadurai. Global Media and Communication 2(1). 7-19.

Stæhr, Andreas. 2015. Reflexivity in Facebook interaction-enregisterment across written and spoken language practices. Discourse, Context \& Media 8. 30-45.

Sharma, Bal Krishna. 2012. Beyond social networking: Performing global Englishes in Facebook by college youth in Nepal. Journal of Sociolinguistics 16(4). 483-509.

Steyaert, Chris, Anja Ostendorp \& Claudine Gaibrois. 2011. Multilingual organizations as 'linguascapes': Negotiating the position of English through discursive practices. Journal of World Business 46(3). 270-278.

Sultana, Shaila. 2014. Heteroglossia and identities of young adults in Bangladesh. Linguistics and Education 26. 40-56.

Sultana, Shaila, Sender Dovchin \& Alastair Pennycook. 2013. Styling the periphery: Linguistic and cultural take-up in Bangladesh and Mongolia. Journal of Sociolinguistics 17(5). 687-710.

Sultana, Shaila, Sender Dovchin \& Alastair Pennycook. 2015. Transglossic language practices of young adults in Bangladesh and Mongolia. International Journal of Multilingualism 12(1). 93-108.

Takahashi, Kimie. 2013. Language learning, gender and desire: Japanese women on the move. Bristol: Multilingual Matters.

Thomas, Angela. 2007. Youth online: Identity and literacy in the digital age. New York: Peter Lang. 
Thorne, Steven L. \& Dejan Ivković. 2015. Multilingual Eurovision meets plurilingual YouTube: Linguascaping discursive ontologies. In Dale A. Koike and Carl S. Blyth (eds.), Dialogue in multilingual and multimodal communities multilingualism. 167-192. Amsterdam: John Benjamins.

Tusting, Karin \& Janet Maybin. 2007. Linguistic ethnography and interdisciplinarity: Opening the discussion. Journal of Sociolinguistics 11(5). 575-583.

Varis, Piia \& Xuan Wang. 2011. Superdiversity on the Internet: A case from China. Diversities 2. $69-81$. 